\title{
Note on Translations and Transliteration
}

Most translations in this book are my own and reflect my understanding of the original Greek. Where I have used English translations of others, I indicate the translator's name or the title of the translated publication.

In transliterating modern Greek terms, I have followed the phonetic system of the Journal of Modern Greek Studies, which reproduces the sound as opposed to the spelling of Greek words. Transliterated words of more than one syllable normally bear a stress accent. I retain wellknown Latinizations or Anglicizations of proper names, place-names, and Greek words that circulate in English. The names Elytis and Seferis and the river Ilissus, as well as the names of ancient authors and heroes and words like topos and cosmos, are prominent examples of this practice. For ancient and Byzantine Greek names, I have followed the more traditional, nonphonetic system of transliteration, in which each Greek letter is rendered into English, and accents are omitted. I follow these two different systems for modern and ancient transliteration because their phonetics differ; furthermore, there is a lack of consensus on ancient Greek pronunciation. 



\section{TOPOGRAPHIES}

OF HELLENISM 
